\title{
LISTA DE PARES
}

"Carlos Alberto Acevedo

carlosacevedo@itm.edu.co;

carlosalberto.acevedo@gmail.com

evelyna@epm.net.co

Doctor en Filosofía de la Ciencia y Gestión de la Innovación Tecnológica"

"Alexander Blandón López

BLANDON 2008@hotmail.com; ablandonl@ut.edu.co

PhD"

"Nelson Riveros Leal

Magister en Ciencias Políticas

nelson.riveros@utadeo.edu.co"

"Charles Robín Arosa Carrera

carosa@unillanos.edu.co

Magister en Mercadeo"

"Denise Caroline Argülles

$\mathrm{PhD}$

darguelles@universidadean.edu.co"

"Manuel Alfonso Garzón

PhD

manuelalfonsogarzon@gmail.com ; manuelalfonsogarzon@fidee.org"

"Luis Carlos Arraut

luisarraut@hotmail.com"

"Juan Carlos Aguilar

Magister

jagui7@yahoo.com" 